\title{
Obstetric Hysterectomy and Maternal Survival
}

Baral J11, Gurung G1, Rana $A^{1}$, Manandhar B ${ }^{1}$, Manandhar $\mathbf{R}^{1}$, Sharma $\mathbf{J}^{1}$, Panta PR ${ }^{1}$, Pradhan $\mathbf{N}^{1}$, Rizal $H^{1}$, Deo $A^{2}$, Singh $A^{2}$, Bhattarai $U^{3}$, Lamichhane $B^{4}$, Kaudel $S^{5}$, Shrestha $D^{1}$, Chudal $D^{1}$, Ahemed $\mathbf{Z}^{1}$, Pokharel $\mathbf{A}^{1}$

${ }^{1}$ Department of Obstetrics and Gynaecology, TU Teaching Hospital, Kathmandu, ${ }^{2}$ Department of Obstetrics and Gynaecology, Nobel Medical College, Biratnagar, ${ }^{3}$ Department of Obstetrics and Gynaecology, Manmohan Memorial Hospital, Kathmandu, ${ }^{4}$ Department of Obstetrics and Gynaecology, Patan Hospital, Lalitpur, ${ }^{5}$ Department of Obstetrics and Gynaecology, Chitwan Medical College, Bharatpur, Nepal

Received: November 5, 2014; Accepted: December 7, 2014

Aims: This study was done to analyze the cases of obstetric hysterectomy and maternal complications and survival after that.

Methods: A retrospective study was carried out from the review of records of the near miss, maternal mortality, cesarean audit and operation theater record of the Department of Obstetrics and Gynaecology, Tribhuvan University Teaching Hospital (TUTH), Kathmandu from 2057-2071 BS.

Results: Fourteen maternal survival resulted following total of 19 obstetric hysterectomy, subtotal hysterectomy being the procedure of choice in 11 cases, emergency peripartum hysterectomy (EPH) being performed in abundance (18/19) in comparison to an elective peripartum hysterectomy, which was undertaken in a single case of placenta percreta, and inclusive of latter were four cases of morbid placental adhesion, a placenta increta and two placenta accreta. Eight out of 19 cases had vaginal delivery and rest had cesarean section. Among seven cases of cesarean hysterectomy 3 were done for placenta previa with accreta one case each done for abruptio placentae and placenta accreta and two cases were done for extra placental causes. Among four cases of emergency peripartum hysterectomy (EPH), which were relaparotomy followed by hysterectomy, three cases were done for complication of cesarean section and one done for uterine atonicity. Four cases of spontaneous vaginal deliveries needed peripartum hysterectomy two of them were complicated by morbid placental adhesion placenta increta (1), placental percreta (1), two cases were vaginal birth after cesarean (VBAC). Seven cases of uterine rupture had undergone peripartum hysterectomy.

Conclusions: Obstetric hysterectomy is a lifesaving surgical procedure for maternal survival whenever necessary and mandates a quick decision making process, however in consideration of younger age and low parity or nulliparity, the best obstetric governance and services must foresee not to let mothers meet such situation necessitating organ removal and to enjoy potential reproductive life cycle.

Keywords: cesarean hysterectomy; emergency peripartum hysterectomy; obstetric hysterectomy.

\section{INTRODUCTION}

Obstetrical hysterectomy includes cesarean hysterectomy, the one that is undertaken at or during cesarean section. Peripartum hysterectomy is defined as the removal of the uterus at the time or within 24 hours of delivery (vaginal or cesarean) or any time from delivery to discharge during the same hospitalization. ${ }^{1,2}$ The operation is either emergent or planned. Emergent is undertaken whenever there is severe uterine hemorrhage that cannot be controlled by conservative measures and they are

\section{CORRESPONDENCE}

Dr Josie Baral

Department of Obstetrics and Gynaecology, TU Teaching Hospital, Kathmandu, Nepal.

Email: baraljosie@gmail.com

Phone: +977-9851104335 abnormal placentation, uterine atony, uterine rupture, leiomyoma and lastly, laceration of uterine vessels. It is undertaken as elective procedure whenever there is antepartum diagnosis of placenta accreta, severe postpartum infection unresponsive to medical therapy or rarely cervical carcinomas stage IA2 and IB1. In the recent years, most of the obstetricians would prefer to save the uterus embracing various ways to combat postpartum hemorrhage through technological advancements unless there is concern for saving the mother's life. In this regard, this study was done to share experiences of the peripartum hysterectomy and to disseminate how important it is for mothers to live, even without uterus. 


\section{METHODS}

This retrospective descriptive study was conducted at Tribhuvan University Teaching Hospital in Kathmandu, having an average annual delivery of 3,500. Records of obstetric hysterectomy, cesarean or peripartum were collected from maternal mortality forms from $2057 \mathrm{BS}$ onwards and also near miss review forms from 2062 BS onwards. Labor room audit, cesarean audit and operation theater audit were also checked to fill in the missed cases if present. All the cases of the obstetric hysterectomy thus retrieved from departmental audit of maternal mortality, near misses, labor room, cesarean and general operation were grouped into cesarean hysterectomy or peripartum hysterectomy and analyzed for the indications and maternal outcome after the procedure.

\section{RESULTS}

There were 14 maternal survivals amongst 19 cases of obstetric hysterectomy performed, 11 of them being subtotal hysterectomy and all but one case of EPH, over the study period of 15 years 2057-2071 BS (April 2000 - Nov 2014).

\begin{tabular}{|c|c|c|c|c|c|c|}
\hline Type & $\begin{array}{l}\text { Causes/ } \\
\text { indications }\end{array}$ & \multicolumn{2}{|c|}{ Details } & MM & NM & TOTAL \\
\hline \multirow{6}{*}{$\begin{array}{l}\text { Caesarean } \\
\text { Hysterectomy }\end{array}$} & \multirow[t]{5}{*}{ Placental (5) } & \multirow{3}{*}{ LUS } & Placenta & {$[1]$} & 1 & 2 \\
\hline & & & Previa & & & \\
\hline & & & $\begin{array}{l}\text { Placenta previa } \\
\text { Acrreta }\end{array}$ & & 1 & 1 \\
\hline & & \multirow[t]{2}{*}{ UUS } & $\begin{array}{l}\text { Abruptio } \\
\text { placenta }\end{array}$ & {$[1]$} & & 1 \\
\hline & & & $\begin{array}{l}\text { Placenta } \\
\text { accreta }\end{array}$ & & 1 & 1 \\
\hline & Extraplacental (2) & & & & & 2 \\
\hline \multirow{5}{*}{$\begin{array}{l}\text { Peripartum } \\
\text { Hysterectomy }\end{array}$} & $\begin{array}{l}\text { Caeseraen Section } \\
\text { (4) }\end{array}$ & Complications & & {$[2]$} & $1+1^{*}$ & 4 \\
\hline & \multirow{4}{*}{$\begin{array}{l}\text { Vaginal delivery } \\
\text { (8) }\end{array}$} & Spontaneous & & {$[1]$} & $1 *$ & 2 \\
\hline & & IOL/UT RUP & & & $2 *$ & 2 \\
\hline & & VBAC & & & $2 *$ & 2 \\
\hline & & Retained pla & & & $1+1 *$ & 2 \\
\hline
\end{tabular}

NB: The number within the [] in bold shows maternal mortality and the number inside () shows severe acute maternal morbidity. The star* shows the uterine rupture. MM- maternal mortality, NM- near miss, UUS- upper uterine segment, LUS- lower uterine segment, UT RUP- uterine rupture, IOL-induction of labor

Cesarean hysterectomy $(\mathrm{CH})$ was done in seven cases out of the 19 and all were undertaken for hemorrhagic complications arising from placenta previa (2), placental abruption (1), placenta acrreta (1), placenta previa accreta (1) and two due to extra placental causes. One was due to atonic primary postpartum hemorrhage refractory to the medical treatment and the other was failure of B- Lynch suture.

Remaining twelve cases were peripartum hysterectomy, all except one was done as emergency basis, eight-followed vaginal delivery and fourfollowed cesarean. One of four cases that followed
CS resulted from atonic primary PPH. Three cases were hemorrhagic complications during cesarean section, such as bleeding from uterine incision angle (1), huge bilateral hematoma (1) and a missed uterine rupture at $\mathrm{CS}$ for second twin with transverse lie and obstructed labor, first twin being born at home. As mentioned above, eight cases of peripartum hysterectomy were done for complication noted at or after planned vaginal deliveries, two each representing spontaneous vaginal delivery, induced vaginal delivery, vaginal birth after cesarean (VBAC) and above all had retained placenta. 
Two cases of EPH were performed after complication of spontaneous vaginal delivery. Indication was torrential bleeding from multiple vaginal tear in a young primigravida who ultimately died despite of the surgical step. In another case the indication was traumatic PPH due to cervical tear extending upto the lateral border of the uterus causing huge broad ligament hematoma.

Two cases had induction of labour one with tab misoprostol 25 mcg 2 doses 4-6 hours apart and another with intracervical dinoprostone gel (cerviprime) $0.5 \mathrm{mg}$, two doses six hours apart. Induction in the first case was done for severe preeclampsia, who experienced excruciating pain and subsequently collapsed after vomiting on laparotomy, 3.5 $\mathrm{L}$ of hemoperitoneum and uterine rupture was observed (Figure 1).

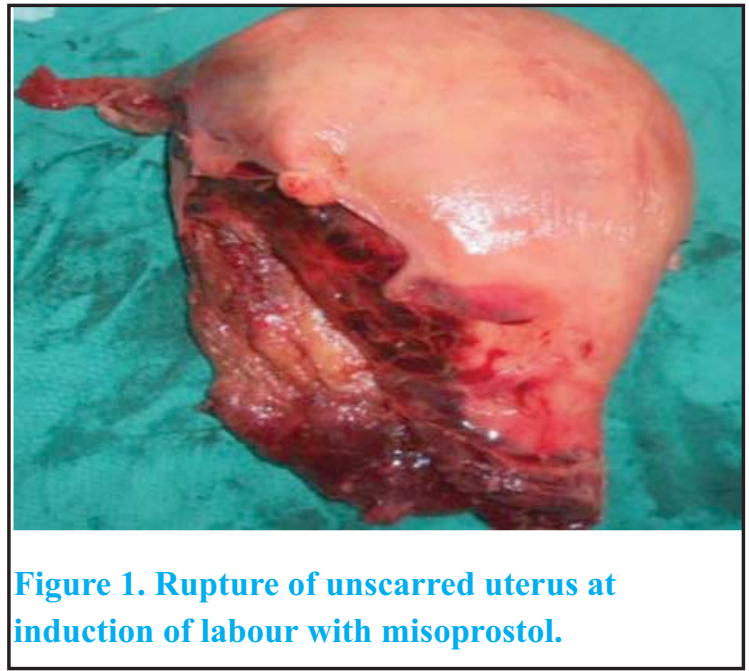

The other case of postdated pregnancy at $41+2$ weeks induced by dinoprostone gel suffered hypotensive collapse just after delivery. On laparotomy, uterine rupture was found. Among two cases of vaginal birth after cesarean (VBAC) and EPH, noteworthy of mention is the rupture of previous cesarean inverted $\mathrm{T}$ scar (Figure 2).

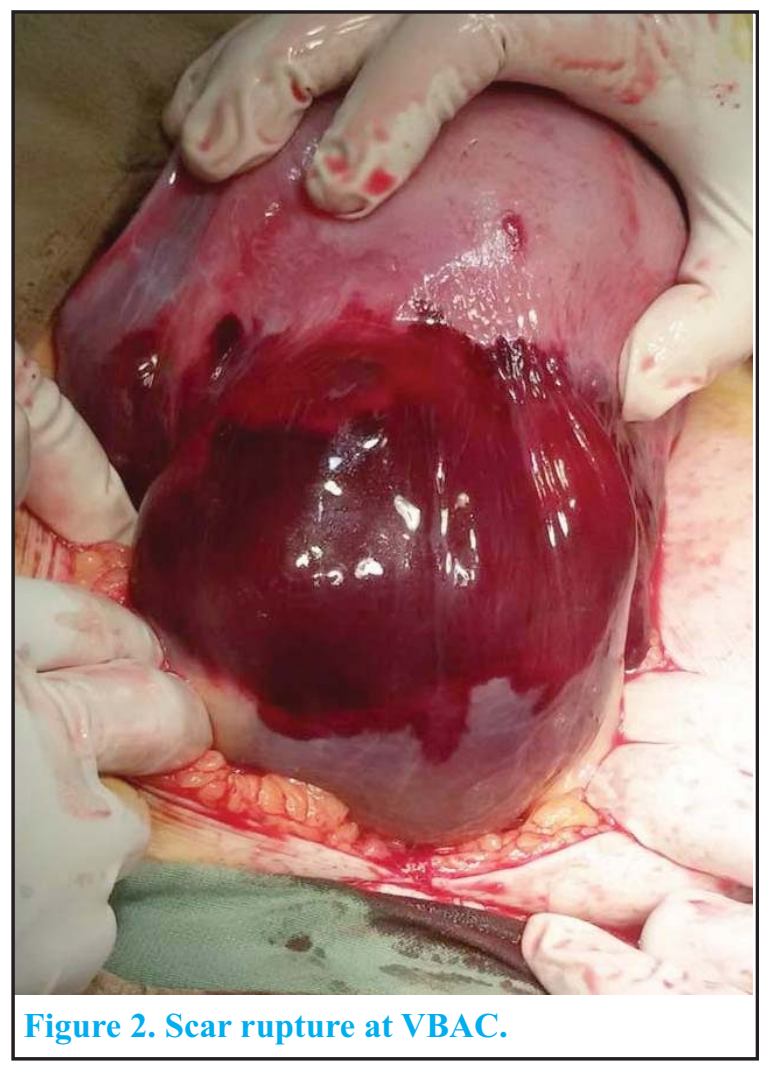

One case survived following two laparotomy and vaginal packing under general anesthesia, had DC shock given twice at two occasions and transfusion of 43 units of whole blood and over 20 units of fresh frozen plasma and platelet rich plasma. Incomplete expulsion of placenta, or rather partial retention of placenta occurred in two cases. In the first, postpartum collapse occurred after spontaneous preterm fresh stillbirth, laparotomy revealed 3.5 L hemoperitoneum, bleeding vessel of placenta percreta situated in the uterine cornua. Last of all that needs mention, is a referred case from Khotang, an 42 years para 7 who was admitted with the diagnosis of placenta increta following preterm vaginal delivery, she was managed by elective peripartum subtotal hysterectomy (Figure 3-4). 

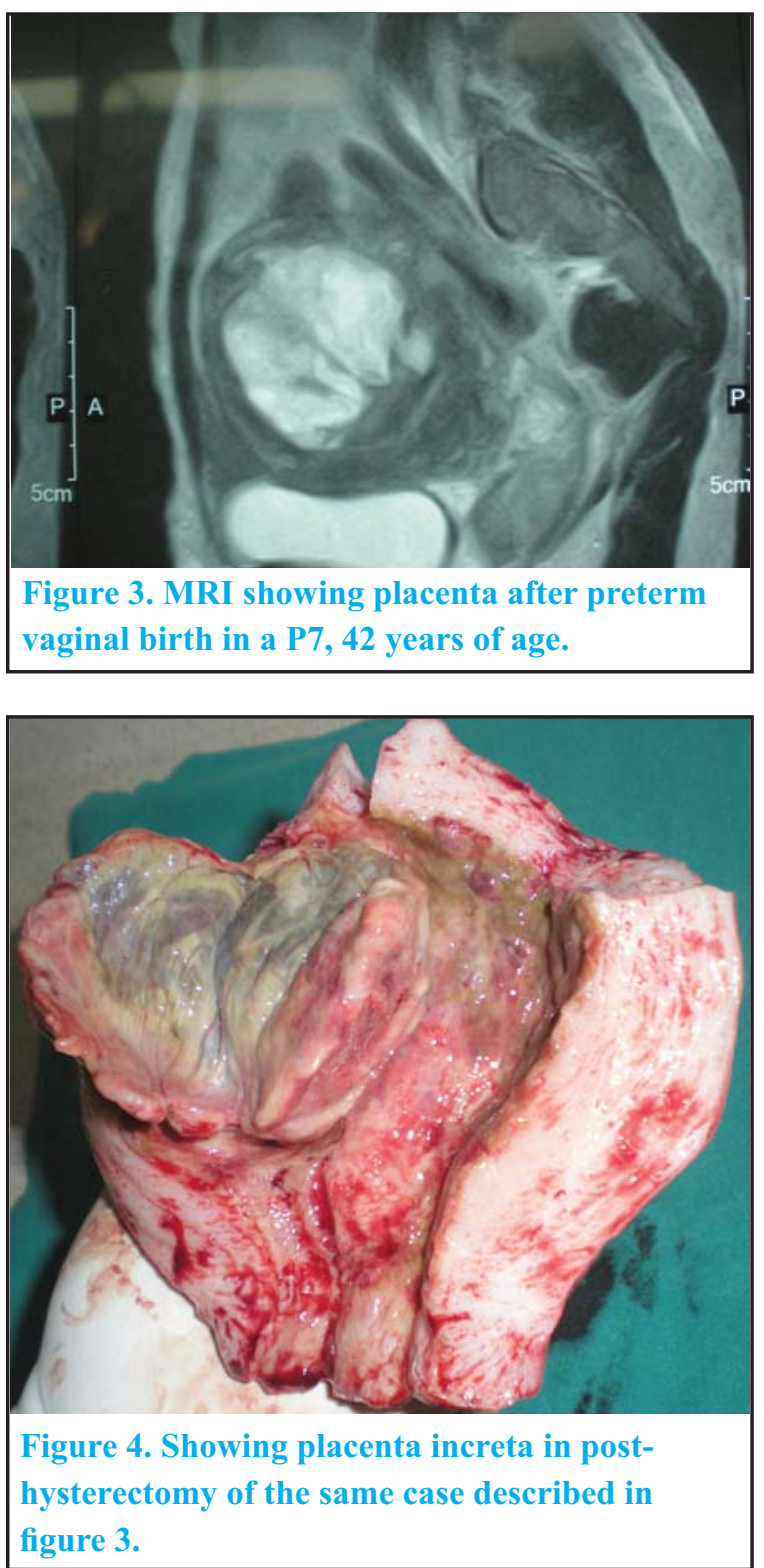

To summarize, there were four cases of morbid adhesion of placenta, two cases of placenta accreta, one in a central placenta previa with accreta, placenta increta and placenta percreta, latter, which perforated the uterus with resultant hemoperitoeum described just above. Including this case of placenta percreta, total seven cases of uterine rupture were responsible for the peripartum hysterectomy. There were two cases of twin, both of them had first vaginal delivery by vertex at home and hospital and second twin CS for transverse lie.

Blood loss or hemoperitoneum ranging from 1 to 4 litres was noted in 10 cases. Maximum number of blood transfusion (only red cell) was 43 units, 11 unit for abruption followed by 8 unit (2), 6 unit (1) and 5 unit (3). $\mathrm{Hb}$ level was seen as low as $2 \mathrm{gm} \%$.

Median age (18-42) was 27 years, regarding gravidity of the cases 4 cases were primigravida and 15 were multigravida, among whom two were grand multigravida.

\section{DISCUSSION}

This study showed a small number of obstetric hysterectomies, not even one per annum which may be because of the technical advancement and choices for medical and surgical management of postpartum hemorrhage, also because of the reservation of surgeons to hysterectomy in consideration to the younger age and low parity. While on the other side, there are mothers who died, either because hysterectomy was avoided or decided too late without much maternal benefit, severe acute maternal morbidity worsening to mortality.

This study indicated obstetric hysterectomy or emergency peripartum hysterectomy, which in true sense followed three cases of vaginal deliveries. One after spontaneous vaginal delivery and ragged vaginal tear, second VBAC and scar rupture and thirdly retained placenta which was indeed placenta percreta perforating uterus.

The fourth case, of induced vaginal deliverywith uterine rupture and partial extrusion of fetal breech in the abdominal cavity, after all is laparotomy and delivery of partially extruded fetus with hysterectomy. These have been disseminated through large studies from $\mathrm{Utah}^{3}$ and addressed by parallel studies of relaparotomy after cesarean. ${ }^{4}$

Refocusing on EPH, arising from post vaginal delivery complications, as already mentioned is placenta precreta. Some of the cases have been mentioned, including intra-abdominal collection., 5,6 In our case, failure to complete placental delivery was a signalfor morbidly adherent placenta which was not understood in the first place. Apart from this, postpartum hemorrhage has been a complication of simple vaginal tear met in our case which resulted without instrumentation. ${ }^{7.8}$ The experiences, have taught us that all the cases of induction of labour has to be properly assessed and well monitored so 
that uterine rupture and its sequel can be minimized. Uterine rupture has been reported with the usage of both dinoprostone and misoprostol in unscarred uterus. ${ }^{9-11}$ Besides this, the rupture of previous cesarean scar to the extent, mandating hysterectomy is an important aspectas well, faced in one of the case detailed above, an issue of concern. ${ }^{12}$

\section{CONCLUSIONS}

Obstetric hysterectomy, a life saving measures must be advocated whenever and wherever the situation necessitates, however in view of maternal interest with regards to low parity and younger age at pregnancy in this part of the world, obstetric services and facilities should be such that the situations mandating EPH does not arise at all.

\section{DISCLOSURE}

The authors report no conflicts of interest in this work.

No violation of human rights and safety.

Funding: Nil

\section{REFERENCES}

1. Turner MJ. Peripartum hysterectomy: an evolving picture. Int J Gynaecol Obstet. 2010; 109(1):9-11. doi: 10.1016/j. ijgo.2009.12.010. Epub 2010 Feb 20.

2. Abasiattai AM, Umoiyoho AJ, Utuk NM, Inyang-Etoh EC, Otobong A, Asuquo P. Emergency peripartum hysterectomy in a tertiary hospital in southern Nigeria. Pan African Medical Journal. 2013;15:60. doi:10.11604/pamj.2013.15.60.1879

3. Shellhaas CS, Gilbert S, Landon MB, Varner MW, Leveno $\mathrm{KJ}$, Hauth JC, et al. The frequency and complication rates of hysterectomy accompanying Cesarean Delivery. Obstet Gynecol.2009;114(2 Pt 1):224-9. doi:10.1097/ AOG.0b013e3181ad9442.

4. Ashwal E1, Yogev Y, Melamed N, Khadega R, Ben-Haroush A, Wiznitzer A, Peled Y. Characterizing the need for relaparotomy during puerperium after cesarean section. Arch Gynecol Obstet. 2014;290(1):35-9. doi: 10.1007/s00404-0143156-1. Epub 2014 Feb 1.

5. Topuz S. Spontaneous uterine rupture at an unusual site due to placenta percreta in a 21-week twin pregnancy with previous cesarean section. Clin Exp Obstet Gynecol. 2004;(3):239-41.

6. Seoud M, Cheaib S, Birjawi G, Tawil A, Jamali F. Successful treatment of severe retroperitoneal bleeding with recombinant factor VIIa in women with placenta percreta invading into the left broad ligament: unusual repeated ante-partum intraabdominal bleeding. J Obstet Gynaecol Res. 2010;36(1):1836. doi: 10.1111/j.1447-0756.2009.01098.x.
7. Maraux B1, Ricbourg A, Brugier C, Chagnaud S, Fargeaudou Y, Rossignol M, Barranger E. Post-partum haemorrhage associated with genital tract lacerations: series of 44 cases. Gynecol Obstet Fertil. 2013;41(12):692-5. doi: 10.1016/j. gyobfe.2012.09.027. Epub 2012 Oct 23

8. Buzaglo N1, Harlev A, Sergienko R, Sheiner E. Risk factors for early postpartum hemorrhage (PPH) in the first vaginal delivery, and obstetrical outcomes in subsequent pregnancy. J Matern Fetal Neonatal Med. 2014;5:1-6.

9. Mizutamari E, Honda T, Ohba T, Katabuchi $H$. Spontaneous rupture of an unscarred gravid uterus in a primigravid woman at 32 weeks of gestation. Case Rep Obstet Gynecol. 2014;209585. doi: 10.1155/2014/209585. Epub 2014 Jun 30.

10. Akhan SE1, Iyibozkurt AC, Turfanda A. Unscarred uterine rupture after induction of labor with misoprostol: a case report. ClinExp Obstet Gynecol. 2001;28(2):118-20.

11. Segal D1, Marcus-Braun N, Katz M. Extrusion of fetus into the abdominal cavity following complete rupture of uterus: a case report. Eur J ObstetGynecolReprodBiol. 2003;1;109(1):1101.

12. Buhimschi CS1, Buhimschi IA, Patel S, Malinow AM, Weiner CP. Rupture of the uterine scar during term labour: contractility or biochemistry? BJOG. 2005; 112(1):38-42. 